\title{
PERSPECTIVES Clinical specialists as digital leaders
}

\author{
Author: Helen Parrott ${ }^{A}$
}

KEYWORDS: Digital leaders, cystic fibrosis, physiotherapy

DOI: 10.7861/fhj.dig-2020-lead

\section{Physiotherapy}

Looking back, physiotherapy for me was an obvious career choice. I had always wanted to understand how to help others use what they had in body and mind to achieve their goals. Early in my NHS career I found a preference for working with people with longterm conditions and came to learn that you had to understand the person before you can understand the health-related behaviour. When I started a post on an adult cystic fibrosis unit, it felt like I had found my place in the NHS. Cystic fibrosis (CF) is such an individual condition that, even with the same genetic mutations, no two people will have exactly the same experience of living with CF. As a CF physiotherapist, while you can never fully understand, you have to get as close as you can to that person's experience in order to find treatments, options and solutions that will work for that individual. I learnt that despite the scientific rationale behind the treatment, if it doesn't fit the individual, you find another one, trial it, evaluate your findings and if it fails, you dust yourself off together and you try something new. My role was a mix of trainer, coach, negotiator, motivator and experimenter, and I loved it.

\section{Cystic fibrosis}

Life expectancy and quality of life for people with CF has significantly improved over the last 10 years, however, this brings the challenge of providing excellent quality and responsive healthcare with growing patient numbers and expectations. ${ }^{1}$ During this time, healthcare teams had been urged to consider providing telehealth as an option for routine monitoring in CF with benefits recognised both to the patient experience and in allocating hospital resources. ${ }^{2}$ As a CF physiotherapist, this gave me a deep sense of purpose. And I felt a duty to fully understand this problem to scope out potential solutions. My career journey in digital health has partnered clinical specialism, independent prescribing and quality improvement, and improving the patient experience has been at the heart of it all.

Author: ${ }^{\text {A }}$ linical lead, NuvoAir, Stockholm, Sweden

\section{Understanding our patients \\ Case example}

At 39, looking after her health was almost a full-time job for Lisa. For Lisa, CF was associated with frequent hospital appointments, six to eight per year, to monitor her health and modify treatments. Lisa found attending clinic at her CF centres exhausting, with a 2-hour journey both ways and squeezing in her treatments around it, she would often report that it took 2-3 days to recover.

She also found she was very anxious about doing her lung function test in clinic, never sure whether the result would be better or worse and if it would mean she might need to stay in hospital for treatment.

She was sure that if she could monitor her own health from home and have virtual consultations instead of so many clinic appointments that it would improve her quality of life. Lisa's ambition was shared among many.

\section{Discussion}

People with CF travel from all over the UK for specialist care and have clinic appointments at least 2-3-monthly for regular monitoring of their health. ${ }^{3}$

Time off work, arranging childcare and the, often significant, cost of travel to the hospital clinic have been cited as impacting on quality of life.

In addition, CF outpatient services are busy and frequently overbooked which was a growing concern given that forecasting in this area has predicted an increase in the number of people with CF by approximately $50 \%$ by 2025 . $^{4}$

\section{Independent prescribing}

Working in one of the largest adult CF centres in Europe, it was easy to stay abreast of developments in new drugs, treatments and care approaches. As I progressed to therapy team leader and extended my scope of practice as an independent prescriber, I was filled with ideas of how what we could change to improve the service for patients and staff. Independent prescribing for physiotherapists was introduced in the UK in 2012 with the first prescribers qualified by 2013. ${ }^{5}$ Non-medical prescribing is now a common area of advancing clinical practice and has been recognised for enabling patients to benefit from receiving holistic care from a single experienced healthcare professional with the potential to reduce delays and access to treatments. ${ }^{6}$ Like any very busy, resource limited NHS team, I was always looking for ways in which we could become more efficient. Working as a non-medical 
prescriber within the team allowed processes to be streamlined and waiting times for inhaled medications to be reduced.

Extending my scope of practice this way felt like a natural step to optimising my value as a clinician.

\section{Quality improvement}

I felt lucky, I had an energy-filled team, a great senior manager and I felt hugely empowered to make change. But change was hard. After failing in a lot of improvement projects and only succeeding in a few (a lot of energy spent in the process), I reflected on the common denominator for success in that very small number of projects. If I was going to embark on successful digital transformation for the CF service, how would I set myself up for success? The answer was, of course, service user involvement. The projects that had embedded the experience and opinions of service users had been successful and led to a better future state or a better improvement idea, also experienced by others who have adopted a more iterative, user-centric process for service development. ${ }^{7}$

Codesigning and producing service improvements with service users has been well documented by researchers as adding significant value to the final improvement intervention placing the patient and staff experience and views at the heart of the improvement effort. ${ }^{8-10}$ The impact of current care models on people with CF and their experience of care was one of the main drivers of the digital programme, therefore, engaging the patients in the potential solution felt like a natural step. In addition, there are signals from the literature that health technologies are at high risk of failure through mistrust and lack of future engagement unless they are co-produced with service users. ${ }^{11}$ Connecting what I had practiced as a clinician with what I now know about designing and measuring improvement gave me the confidence to forge forward as a digital change agent.

\section{Codesigning digital solutions for cystic fibrosis care}

Our codesigned solution for improving the lives of people with cystic fibrosis involved two aspects of digital transformation: the provision of hand-held home spirometry to help monitor lung health remotely and a change to the care model to incorporate virtual consultations. It's hard to believe this now, given the acceleration in digital change as a result of the COVID-19 pandemic but, at the time, combining these ambitions was considered an untrodden, innovative path. ${ }^{12}$ By 2017, I held a trustwide leadership role in therapy services but continued to spend a small percentage of my time leading the digital innovation programme for the CF service. I loved this hybrid role opportunity; the leadership experience I was gaining helped me to understand the conditions I needed for people to go on this digital journey with me: trust, honesty and open communication. The digital innovation side exposed me to completely new challenges, such as elevator pitching, fundraising, meeting information governance requirements, running a competitive NHS tender and evaluating the security of video consultation systems, to name just a few!

\section{Digital competencies}

I was given the opportunity to complete Masters modules in 'innovation in healthcare' supported by my local Academic Health Science Network and, in 2018, I joined the first Digital Pioneer Fellowship run by Digital Health.London (https://digitalhealth.london).
These opportunities were everything I had needed and more. They offered the peer support I had been craving but also provided a systematic approach to innovation that gave me the confidence and credibility to present a compelling argument to stakeholders why this digital programme should come to fruition (https://digitalhealth. london/self-monitoring-bridging-the-gap-between-intention-andaction). I learnt how to present and use theories of change when the outcome is unknown, the importance of understanding the process of behaviour change and how to write a compelling business case based on modelling the economic impacts. ${ }^{13,14}$

These programmes taught me what so many esteemed others already knew: it's not the technology that makes the change, it's the people. You can have the best technology solution but if you can't make it work for the people and solve a problem for the people, the change will struggle to be sustained. It reconnected me to my purpose as a clinician, to understand, as close as possible, the experience and solution from the perspective of others.

\section{Digital innovation}

The digital solution you will find in use in the CF service today involved a collaboration with a digital health company, NuvoAir www.nuvoair.com, and also significant service redesign by the clinical team to make the changes needed to improve the patient experience and future-proof the service. Delivering the digital ambitions in partnership with a technology company from outside the NHS has not been without its challenges but, on balance, it has been a partnership to be proud of with outcomes such as a $30 \%$ reduction in clinic attendance (prior to COVID-19), significant time and cost of travel saved and an improved understanding of health for people with CF. The collaboration was recognised at the 2020 HS] Awards, winning HealthTech Partnership of the Year. ${ }^{15}$ When scoping out potential solutions at the beginning of this journey, I first believed we would need to start from scratch, maybe even establish our own company. I had no idea that there were technology companies already out there who are fiercely driven by improving the quality of life of people living with longterm conditions, and now I have had the pleasure of meeting so many of them! How naive I was to think this was a trait reserved only for the clinician, and how exciting for these worlds to come together to solve problems in the NHS. A vanguard of this being the hugely successful NHS clinical entrepreneurs programme I have been so excited to be part of this year. ${ }^{16}$ The programme, led by Prof Tony Young, the national clinical lead for innovation at NHS England, offers an opportunity for NHS professionals to pursue entrepreneurial and intrapreneurial aspirations as part of the biggest entrepreneurial workforce development programme of its kind. It recognises the value of combining NHS experience and an entrepreneurial mindset to generate and scale innovative ideas, giving the founders and innovations the best chance of success through expert guidance and mentorship, business and commercial knowledge exchange, leadership development and more.

\section{Realising the potential for cystic fibrosis self-monitoring}

The CF team are now fully established in their programme of digital transformation and continue to scale up the offer of self-monitoring and virtual consultations to their whole cohort of nearly 600 adults with cystic fibrosis. They continue to be commended for their approach and are often invited to present at 
conferences on their learning and their future care model in caring for people with cystic fibrosis. I am so proud to have played a part in that progress.

I now work as clinical lead for the digital health company, NuvoAir. It was a hard decision for me to move outside of the NHS but it felt like a meaningful next step to apply my clinical leadership to help a digital product that I believe in. My experiences, both as a digital change agent in the NHS and now working for a digital health small-/medium-sized enterprise, have convinced me that successful technology adoption requires more than the provision of the digital tool or technology solution. It also needs people: people willing and able to help redesign clinical pathways, support digital literacy and to develop onboarding and evaluation plans.

\section{A new identity as a clinical leader in digital health}

Years ago, I worried about protecting my identity as a clinician. But today, I feel hugely valued and excited by the diverse way I am able to use my clinical knowledge and experience to help people with long-term conditions and continue to be inspired by the teams and clinicians I meet along the way. I support clinical teams across the globe to adopt and successfully implement a solution that remotely monitors lung function and helps to predict the healthcare needs of people with long-term respiratory conditions. I also get to share feedback with the team directly from patients and clinicians to help develop the technology, continuing to connect with my purpose of understanding the experience of others and improving the lives of people with long-term conditions.

\section{References}

1 UK CF Registry. 2018 annual data report. Cystic Fibrosis Trust, 2018. www.cysticfibrosis.org.uk/the-work-we-do/uk-cf-registry/reportingand-resources

2 National Institute for Clinical Excellence. Cystic fibrosis: diagnosis and management: NICE guideline [NG78]. NICE, 2017. www.nice. org.uk/guidance/ng78

3 Cystic Fibrosis Trust. Standards for the clinical care of children and adults with cystic fibrosis in the UK. Cystic Fibrosis Trust, 2011. www.cysticfibrosis.org.uk/the-work-we-do/resources-for-cf-professionals/consensus-documents
4 Burgel PR, Bellis G, Olesen HV et al. Future trends in cystic fibrosis demography in 34 European countries. Eur Respir ] 2015;46:133-41.

5 Chartered Society of Physiotherapy. Medicines, prescribing and injection therapy. CSP, 2012. www.csp.org.uk/professional-clinical/ professional-guidance/medicines-prescribing-injections

6 Graham-Clarke E, Rushton A, Noblet T, Marriott J. Non-medical prescribing in the UK NHS: A systematic policy review. PLOS ONE 2019;14:e0214630.

7 Woods L, Cummings E, Duff J, Walker K. Conceptual design and iterative development of an mHealth app by clinicians, patients and their families. Stud Health Technol Inform 2018;252:170-5.

8 Piper D, Iedema R, Gray ] et al. Utilizing experience-based co-design to improve the experience of patients accessing emergency departments in the New South Wales public hospitals: an evaluation study. Health Serv Manage Res 2012;25:162-72.

9 Coyne I, Prizeman G, Sheehan A, Malone H, White AE. An e-health intervention to support the transition of young people with longterm illnesses to adult healthcare services: Design and early use. Patient Educ Couns 2016:99:1496-504.

10 Morton M, Paice E. Co-production at the strategic level co-designing an integrated care system with lay partners in north west London, England. Int J Integr Care 2016;16:2.

11 Pevnick JM, Fuller G, Duncan R, Spiegel BMR. A large-scale initiative inviting patients to share personal fitness tracker data with their providers: initial results. PLOS ONE 2016;11:e0165908.

12 Fisk M, Livingstone A, Pit SW. Telehealth in the context of COVID-19 changing perspectives of Australia, the UK and the US. J Med Internet Res 2020;22:e19264.

13 Stein D, Valters C. Understanding theory of change in international development. The Justice and Security Research Programme, 2012. http://eprints.lse.ac.uk/56359

14 Reed JE, McNicholas C, Woodcock T, Issen L, Bell D. Designing quality improvement: the action effect method, a structured approach to identifying and articulating programme theory. BMJ Qual Saf 2014:23;1040-8.

15 HSJ. HSJ Partnership Awards 2020: HealthTech Partnership of the Year. HSJ, 2020. www.hsj.co.uk/7026767.article

16 NHS. Clinical entrepreneur training programme. NHS. www.england. nhs.uk/aac/what-we-do/how-can-the-aac-help-me/clinical-entrepre neur-training-programme

Address for correspondence: Helen Parrott, NuvoAir, Riddargatan 17D, 11457 Stockholm, Sweden.

Email: helen.parrott@nuvoair.com 